\title{
Admission Anion Gap Metabolic Acidosis and Its Impact on Patients in Medical Intensive Care Unit
}

Akshay Dafal $^{1}$ Sunil Kumar ${ }^{1}$ Sachin Agrawal ${ }^{1}$ Sourya Acharya ${ }^{1} \quad$ Apoorva Nirmal $^{1}$
Address for correspondence Sachin Agrawal, MD, Department of Medicine, Jawaharlal Nehru Medical College, Datta Meghe Institute of Medical Sciences (Deemed to be University), Wardha 442004, Maharashtra, India (e-mail: Dragrawal82@gmail.com).

\begin{abstract}
Keywords

- anion gap

- metabolic acidosis

- intensive care unit
\end{abstract}

\section{Introduction}

The anion gap (AG) is the difference between measured cations such as positively charged ions like sodium $\left(\mathrm{Na}^{+}\right)$and potassium $\left(\mathrm{K}^{+}\right)$and negatively charged ions like chloride $(\mathrm{Cl})$ and bicarbonate $\left(\mathrm{HCO}_{3}\right)$. The most common application of the AG is classifying cases of metabolic acidosis, states of lower than normal blood $\mathrm{pH}^{1}{ }^{1,2}$ It has been shown that patients with high AG have increased rates of admission to intensive care unit, and increased mortality within 1 week of hospital admission compared with patients having a normal AG, independent of concomitant severe electrolyte abnormalities. $^{3-5}$ In critically ill patients, an elevated AG usually reflects an imbalance between acid generation in hypoperfused tissues and the ability of the kidneys to excrete these acids. Thus, the presence of an elevated AG may indicate subtle hemodynamic abnormalities leading to tissue hypoperfusion but not an overt shock. ${ }^{4,5}$ Previous studies had taken only lactic acidosis in consideration among critically ill patients as this is being an indirect marker of metabolic acidosis at the cellular level. ${ }^{6}$ This study had been planned to assess impact of on admission AG with the outcome in terms of length of stay, need of ventilators, mortality in the critically ill patients admitted to medical intensive care unit (MICU) as data from Indian studies are lacking.

\section{published online} June 25, 2021
DOI https://doi.org/ $10.1055 / \mathrm{s}-0041-1726568$ ISSN 0974-2727 (c) 2021. The Indian Association of Laboratory Physicians.

This is an open access article published by Thieme under the terms of the Creative Commons Attribution-NonDerivative-NonCommercial-License, permitting copying and reproduction so long as the original work is given appropriate credit. Contents may not be used for commercial purposes, or adapted, remixed, transformed or built upon. (https://creativecommons.org/licenses/by-nc-nd/4.0/). Thieme Medical and Scientific Publishers Pvt. Ltd. A-12, 2nd Floor, Sector 2, Noida-201301 UP, India 


\section{Methods}

This cross-sectional study was performed in the Medical ICU at rural central India, from September 2017 to March 2019, after approval by the Institutional Ethics Committee.

All consecutive patients above 18 years admitted directly to the critical care unit were screened for inclusion in the study. Patients with $\mathrm{HCO}_{3}$ less than $22 \mathrm{mEq} / \mathrm{L}$ were enrolled in the study.

Patients on mechanical ventilation before the evaluation, transferred to medicine intensive care unit (ICU) from other hospital, post-surgical were excluded from the study.

Arterial blood samples were collected at the time of ICU admission in heparinized blood-gas syringes and analyzed in blood-gas analyzer at $37^{\circ} \mathrm{C}$. Samples were not stored on ice. Data like $\mathrm{pH}, \mathrm{PaCO}_{2}, \mathrm{HCO}_{3}$ were collected from the analyzer output. The samples were analyzed at our central laboratory department for the measurement of multiple biochemical variables including sodium, potassium, and chloride. AG was calculated by the formula [(sodium + potassium) $($ chloride + bicarbonate)].

The patients were divided into the following four groups: non-anion gap having patients with AG $<12$ and $\mathrm{HCO}_{3}<22 \mathrm{mEq} / \mathrm{L}$. Patients with AG $>12$ and $\mathrm{HCO}_{3}<22 \mathrm{mEq} / \mathrm{L}$ were classified into three stages: Stage $1 \mathrm{AG}$ : 12 to $20 \mathrm{mEq} / \mathrm{L}$, Stage 2 AG: 21 to $30 \mathrm{mEq} / \mathrm{L}$, Stage 3 AG: >30 mEq/L. Each group was compared for hematological parameters like hemoglobin level. Leucocyte count, serum electrolytes, kidney and liver function test, and outcome (length of stay in hospital, length of stay on ventilator, and length of stay in ICU) are shown in - Fig. 1.

Sample size calculation was done by using formula, $N=$ $\left(Z^{2} \times P \times(1-P)\right) / d 2, Z 2=$ table value of $\alpha$ error from Standard Normal Distribution table $=1.96 \times 1.96=3.84$, power $(P)=$ $0.05,(1-P)=0.95$, precision error of estimation $(d)=2 \%$, $N=\left(1.96^{2} \times 0.05 \times 0.95\right) / 0.022=465.6$. The sample size of 500 patients was taken for the study.

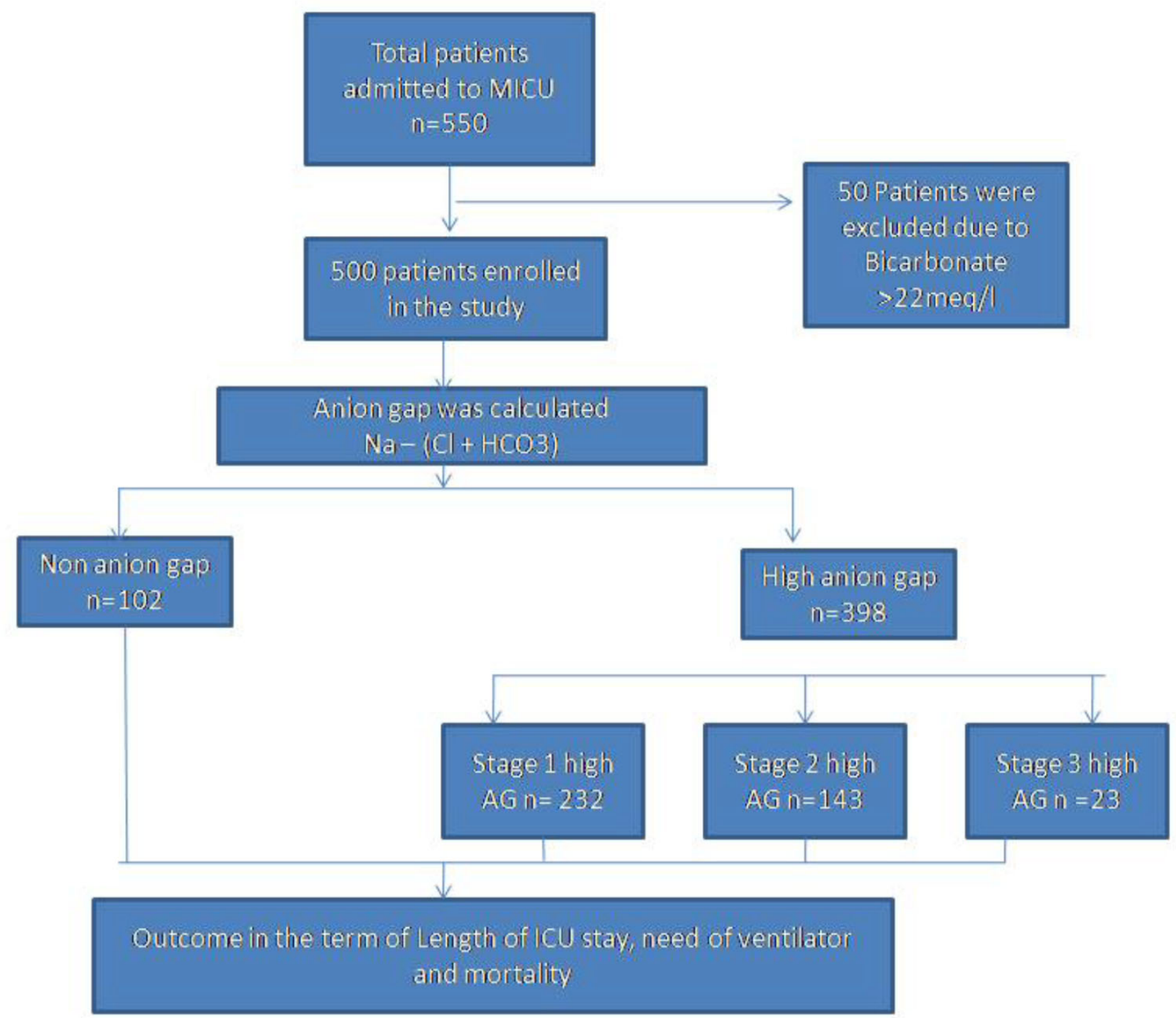

Fig. 1 Flowchart of the study's design. 


\section{Statistical Methods}

Descriptive statistics for all qualitative variables were represented using frequency and percentage. Comparison among the study groups is made with the help of unpaired $t$-test as per results of the normality test. All the quantitative variables were checked for normality assumption and were presented using mean and standard deviation. Association between the groups was assessed using the chi-square test. The association of normally distributed quantitative variables with the groups was measured using one-way analysis of variance (ANOVA) and the association of non-normally distributed quantitative variables with the groups was measured using Kruskal-Wallis test. For all the comparisons, the $p$-value of less than 0.05 was considered statistically significant. The data was entered in Excel (Microsoft Corp.) spreadsheet and analysis was done using Statistical Package for Social Sciences version 21.0 (IBM Inc.).

\section{Observation and Results}

Out of all 500 patients, the mean age of patients in non-anion gap, Stage 1 AG, Stage 2 AG, and Stage 3 AG was $65.70 \pm 10.27$, $48.31 \pm 13.17,42.03 \pm 15.67$, and $55.52 \pm 21.47$ years, respectively which were statistically significant as per the ANOVA test $(p<0.05)$. Other base line characteristics with hematological parameter were shown in - Table 1.

The need of ventilator $(2.52 \pm 0.73,3.31 \pm 1.53,2.96 \pm 1.29$, $3.50 \pm 1.11$, respectively) and length of stay in ICU (3.65 \pm $0.78,3.68 \pm 1.59,4.67 \pm 1.60,5.42 \pm 2.02$, respectively) was significantly lower in non-anion gap compared with Stage 1 AG, Stage 2 AG, and Stage 3 AG as per the ANOVA test $(p<0.05)$ as shown in $\mathbf{- T a b l e} \mathbf{2}$. The mortality in patients was significantly lower [1 (0.98\%), 109 (46.90\%), 112 (78.30\%), 23 (100\%), respectively] in non-anion group compared with Stage 1 AG, Stage 2 AG, and Stage 3 AG as per ANOVA test $(p<0.05)$ as shown in -Table 2 . The need of ventilator ( 1.51 $\pm 2.11,2.81 \pm 1.7$, and $3.63 \pm 1.5$, respectively) and ICU stay $(1.67 \pm 1.2,2.85 \pm 1.65$, and $3.9 \pm 1.23$, respectively) was significantly lower in non-anion group compared with Stage 1 AG, Stage 2 AG as per the ANOVA test $(p<0.05)$ amongst survival group as shown in - Table 3. Patients with Stage 3 AG, however, did not survive.

The need of ventilator $(3.7 \pm 1.2,3.15 \pm 1.65,3.1 \pm 1.23$, and $2.45 \pm 0.6$ days, respectively) and ICU stay (5.51 \pm 2.11 , $4.81 \pm 1.7,3.63 \pm 1.5$, and $3.21 \pm 0.8$ days, respectively) was significantly higher in non-anion group compared with Stage 1 AG, Stage 2 AG, and Stage 3 AG as per ANOVA test $(p<0.05)$ amongst nonsurvival group as shown in - Table 4 . This was because majority of the patients with higher AG died within 2 to 3 days. Whereas patients with higher AG who survived took longer time to recover and hence their length of stay in ICU and on ventilator was more compared with those with non-anion gap.

\section{Discussion}

This study revealed that on admission AG metabolic acidosis in MICU had an impact in terms of mortality, need of ventilators, and length of ICU stays. Higher AG metabolic acidosis was directly related to mortality. An elevated AG usually reflects an imbalance between acid generation in hypoperfused tissues and the ability of the kidneys to excrete these

Table 1 Distribution of patients according to age

\begin{tabular}{|c|c|c|c|c|c|}
\hline Parameters & $\begin{array}{l}\text { Non-anion gap } \\
N=102\end{array}$ & $\begin{array}{l}\text { Stage } 1 \text { AG } \\
N=232\end{array}$ & $\begin{array}{l}\text { Stage } 2 \text { AG } \\
N=143\end{array}$ & $\begin{array}{l}\text { Stage } 3 \text { AG } \\
N=23\end{array}$ & $p$-Value \\
\hline Mean age & $65.70 \pm 10.27$ & $48.31 \pm 13.17$ & $42.03 \pm 15.67$ & $55.52 \pm 21.47$ & $<0.05$ \\
\hline Male & $68(66.7 \%)$ & $168(72.4 \%)$ & $120(83.9 \%)$ & $14(60.9 \%)$ & $>0.05$ \\
\hline Female & $34(33.3 \%)$ & $64(27.6 \%)$ & $23(16.1 \%)$ & $9(39.1 \%)$ & $>0.05$ \\
\hline $\mathrm{Hb}$ & $12.44 \pm 1.32$ & $10.69 \pm 2.10$ & $10.22 \pm 2.30$ & $9.02 \pm 1.24$ & $<0.05$ \\
\hline TLC & $8,008.43 \pm 2515.27$ & $13,232.46 \pm 3831.65$ & $13815.10 \pm 3914.06$ & $15,148.21 \pm 2,058.19$ & $<0.05$ \\
\hline $\mathrm{HCT}$ & $40.35 \pm 4.92$ & $40.20 \pm 4.50$ & $39.71 \pm 6.00$ & $39.79 \pm 1.87$ & $>0.05$ \\
\hline Platelets & $1.67 \pm 0.56$ & $1.34 \pm 0.67$ & $1.24 \pm 0.67$ & $0.70 \pm 0.30$ & $<0.05$ \\
\hline SGOT & $43.85 \pm 2.23$ & $51.46 \pm 3.95$ & $62.03 \pm 3.80$ & $128.65 \pm 9.15$ & $<0.05$ \\
\hline SGPT & $33.07 \pm 2.51$ & $39.82 \pm 4.41$ & $53.25 \pm 7.30$ & $58.30 \pm 1.95$ & $<0.05$ \\
\hline Bilirubin & $1.73 \pm 1.37$ & $1.89 \pm 1.27$ & $2.26 \pm 2.97$ & $2.23 \pm 0.92$ & $<0.05$ \\
\hline Sodium & $139.78 \pm 3.79$ & $143.17 \pm 6.85$ & $146.28 \pm 9.12$ & $151.22 \pm 8.02$ & $<0.05$ \\
\hline Potassium & $3.94 \pm 0.51$ & $4.56 \pm 0.80$ & $4.83 \pm 0.74$ & $5.41 \pm 0.67$ & $<0.05$ \\
\hline Chloride & $107.10 \pm 4.95$ & $112.62 \pm 7.20$ & $116.15 \pm 4.32$ & $123.30 \pm 8.06$ & $<0.05$ \\
\hline Urea & $55.20 \pm 1.59$ & $64.39 \pm 4.43$ & $76.58 \pm 3.58$ & $79.87 \pm 8.78$ & $<0.05$ \\
\hline Creatinine & $1.55 \pm 2.21$ & $1.84 \pm 1.61$ & $1.86 \pm 0.33$ & $2.12 \pm 1.95$ & $<0.05$ \\
\hline $\mathrm{HCO}_{3}$ & $16.98 \pm 2.56$ & $13.74 \pm 3.11$ & $12.03 \pm 2.71$ & $10.52 \pm 2.47$ & $<0.05$ \\
\hline
\end{tabular}

Abbreviations: AG, anion gap; HCT, hematocrit; ICU, intensive care unit; SGOT, serum glutamic-oxaloacitic transaminase; SGPT, serum glutamicpyruvic transaminase; TLC, total leucocyte count.

Note: Bold values denote statistical significance. 
Table 2 Association of on admission anion gap and outcome

\begin{tabular}{|l|l|l|l|l|l|}
\hline Parameters & $\begin{array}{l}\text { Non-anion gap } \\
N=102\end{array}$ & $\begin{array}{l}\text { Stage 1 AG } \\
N=232\end{array}$ & $\begin{array}{l}\text { Stage } 2 \text { AG } \\
N=143\end{array}$ & $\begin{array}{l}\text { Stage } 3 \text { AG } \\
N=23\end{array}$ & $p$-Value \\
\hline Need of ventilator (d) & $2.52 \pm 0.73$ & $3.31 \pm 1.53$ & $2.96 \pm 1.29$ & $3.50 \pm 1.11$ & $<0.05$ \\
\hline ICU stay (d) & $3.65 \pm 0.78$ & $3.68 \pm 1.59$ & $4.67 \pm 1.60$ & $5.42 \pm 2.02$ & $<0.05$ \\
\hline Mortality & $1(0.98 \%)$ & $109(46.90 \%)$ & $112(78.30 \%)$ & $23(100 \%)$ & $<0.05$ \\
\hline
\end{tabular}

Abbreviations: AG, anion gap; ICU, intensive care unit.

Table 3 Comparison of anion gap and outcome in survival group

\begin{tabular}{|l|l|l|l|l|l|}
\hline Parameters & $\begin{array}{l}\text { Non-anion gap } \\
N=102\end{array}$ & $\begin{array}{l}\text { Stage 1 AG } \\
N=232\end{array}$ & $\begin{array}{l}\text { Stage 2 AG } \\
N=143\end{array}$ & $\begin{array}{l}\text { Stage 3 AG } \\
N=23\end{array}$ & $p$-Value \\
\hline Need of ventilator (d) & $1.51 \pm 2.11$ & $2.81 \pm 1.7$ & $3.63 \pm 1.5$ & 0 & $<0.05$ \\
\hline ICU stay (d) & $1.67 \pm 1.2$ & $2.85 \pm 1.65$ & $3.9 \pm 1.23$ & 0 & $<0.05$ \\
\hline
\end{tabular}

Abbreviations: AG, anion gap; ICU, intensive care unit.

Table 4 Comparison of anion gap and outcome in nonsurvival group

\begin{tabular}{|l|l|l|l|l|l|}
\hline Parameters & $\begin{array}{l}\text { Non-anion gap } \\
N=102\end{array}$ & $\begin{array}{l}\text { Stage } 1 \text { AG } \\
N=232\end{array}$ & $\begin{array}{l}\text { Stage } 2 \text { AG } \\
N=143\end{array}$ & $\begin{array}{l}\text { Stage } 3 \text { AG } \\
N=23\end{array}$ & $p$-Value \\
\hline Need of ventilator (d) & $3.7 \pm 1.2$ & $3.15 \pm 1.65$ & $3.1 \pm 1.23$ & $2.45 \pm 0.6$ & $<0.05$ \\
\hline ICU stay (d) & $5.51 \pm 2.11$ & $4.81 \pm 1.7$ & $3.63 \pm 1.5$ & $3.21 \pm 0.8$ & $<0.05$ \\
\hline
\end{tabular}

Abbreviations: AG, anion gap; ICU, intensive care unit.

acids. Thus, the presence of an elevated AG may indicate subtle hemodynamic abnormalities leading to tissue hypoperfusion but not overt shock. Increased production of negatively charged short-term phase proteins might help explain the increase in $\mathrm{AG} .{ }^{7.8}$

Need of ventilator in terms of days was significantly lower in non-anion group compared with Stage $1 \mathrm{AG}$, Stage $2 \mathrm{AG}$, and Stage 3 AG acidosis. There was a significant increase in length of stay on a ventilator with an increase in severity of AG on admission. Similarly in the study conducted by Kiran et al out of 55 patients who were put on mechanical ventilator on the first day, 45 (81.8\%) patients expired compared with 10 (18.2\%) patients who did not need mechanical ventilation.?

The mean length of stay in ICU was significantly lower in non-anion group compared with Stage 1 AG, Stage 2 AG, and Stage 3 AG. There was a significant increase in length of stay in ICU with an increase in severity of AG on admission. A study had shown that an elevated AG was associated with increased severity of illness including increased likelihood of hospital and ICU admission. ${ }^{5}$

However, it was observed that the mean length of ICU stay and need of ventilator was significantly higher in patients with high AG who survived as compared with nonsurvival patients.

The mortality in patients was significantly lower in non-anion group compared with Stage 1 AG, Stage 2 AG, and Stage 3 AG. There was a significant increase in mortality in patients with an increase in severity of AG on admission. The mean age of the patients in non-anion gap was significantly higher than in patients of high AG. High AG metabolic acidosis may be associated with higher mortality compared with normal AG acidosis as reported by Jung et al, whereas kotake, and Rocktaeschel et al reported no statistical significance in outcomes between these two groups. ${ }^{9-11}$

\section{Limitations}

This study had considered analyzing only "On" admission AG and correlating the outcome in a critically ill patient; hence, we could not predict and correlate the outcome based on serial arterial blood gas analysis and AG calculation. Since our study population included only critically ill patients, we could not correlate AG and its outcome in relatively stable patients. AG was not corrected for albumin level. The mortality of patients could also be related to the underlying etiology which was not noted.

\section{Conclusion}

Patients who were admitted in ICU or those who were critically ill, calculating the AG has played a crucial role in predicting the outcome. Calculating AG (high or normal) will eventually help in identifying the patients in resource-constraint settings where lactate may not be available.

And also in those who are at risk of developing morbidity and mortality and hence the appropriate line of management, in the initial stages, can change the outcome in critically ill patients.

\section{Funding}

The author (s) declared no requirement of financial support. 


\section{Conflict of Interest}

All the authors of the present study declare no conflicts of interest.

\section{References}

1 Berend K, de Vries AP, Gans RO. Physiological approach to assessment of acid-base disturbances. N Engl J Med 2014; 371(15):1434-1445

2 Magder S, Emami A. Practical approach to physical-chemical acid-base management. Stewart at the bedside. Ann Am Thorac Soc 2015;12(1):111-117

3 Masevicius FD, Tuhay G, Pein MC, Ventrice E, Dubin A. Alterations in urinary strong ion difference in critically ill patients with metabolic acidosis: a prospective observational study. Crit Care Resusc 2010;12(4):248-254

4 Tuhay G, Pein MC, Masevicius FD, Kutscherauer DO, Dubin A. Severe hyperlactatemia with normal base excess: a quantitative analysis using conventional and Stewart approaches. Crit Care 2008;12(3):R66
5 Kumar S, Honmode A, Jain S, Bhagat V. Does magnesium matter in patients of medical intensive care unit: a study in rural Central India. Indian J Crit Care Med 2015;19(7):379-383

6 Chen CY, Pan CF, Wu CJ, Chen HH, Chen YW. Bicarbonate can improve the prognostic value of the MELD score for critically ill patients with cirrhosis. Ren Fail 2014;36(6):889-894

7 Kiran HS, Anil GD, Murthy KA, Gowdappa HB. Severe metabolic acidosis in critically ill patients and its impact on the outcome; a prospective observational study. Int J Sci Stud 2015;3(8):168-171. DOI: 10.17354/ijss/2015/533

8 Mehta HJ, Bhanusheli G, Nietert PJ, Pastis NJ. WITHDRAWN: the association between initial anion gap and outcomes in medical intensive care unit patients. J Crit Care 2012;12:S0883-S9441

9 Rocktaeschel J, Morimatsu H, Uchino S, Bellomo R. Unmeasured anions in critically ill patients: can they predict mortality? Crit Care Med 2003;31(8):2131-2136

10 Jung B, Rimmele T, Le Goff C, et al; AzuRea Group. Severe metabolic or mixed acidemia on intensive care unit admission: incidence, prognosis and administration of buffer therapy. A prospective, multiple-center study. Crit Care 2011;15(5):R238

11 Kotake Y. Unmeasured anions and mortality in critically ill patients in 2016. J Intensive Care 2016;4(1):45 